\title{
Hubungan Loneliness dengan Perilaku Cybersex pada Emerging Adult
}

\author{
LAILY AURA NISYA HABIBI \& AFIF KURNIAWAN*
}

Fakultas Psikologi Universitas Airlangga

\section{ABSTRAK}

Pengguna terbesar internet didominasi oleh usia 18-25 tahun (emerging adult), individu pada masa usia ini memiliki tugas perkembangan menjalin intimacy dengan individu lain, apabila individu tidak memenuhi tugas perkembangan, emerging adult dapat mengalami berbagai permasalahan seperti depresi atau merasa kesepian (loneliness). Sebagai upaya mengatasi permasalahan tersebut, emerging adult memanfaatkan internet untuk menjalin relasi dengan individu lain agar tidak merasa kesepian. tetapi, tidak semua yang ada pada internet bersifat positif, dengan adanya internet akses pornografi semakin mudah, sehingga terjadi peningkatan terhadap perilaku cybersex. penelitian ini bertujuan untuk mengetahui hubungan loneliness dengan perilaku cybersex pada emerging adult. Hasil analisis membuktikan hubungan yang dimiliki antara loneliness dengan perilaku cybersex bersifat tidak signifikan. disamping itu hubungan yang terjadi antara loneliness dengan dimensi online sexual behaviorsocial dan online sexual behavior-isolated bersifat tidak signifikan, namun hubungan yang terjadi antara loneliness dengan dimensi interest in online sexual behavior bersifat signifikan.

Kata kunci: cybersex, emerging adult, loneliness

\section{ABSTRACT}

The largest user of the internet are people around 18-25 years old. Emerging adult has developmental task, one of them is having intimacy with others individual. When emerging adult can't fulfill these tasks, they are going to have some issues, like loneliness. In order to fulfill the developmental task, emerging adult usually use internet to communicate with others so they don't feel lonely. But not all things on the internet have a positive impact on emerging adult, there are also many negative impacts because of internet like open access to pornographic, cybersex and others. This research aims to understand the relationship between loneliness and cybersex in emerging adult. The result showed that the relationship between loneliness and cybersex is not significant. The relationship between loneliness and online sexual behavior-social dimensional, and online sexual behavior-isolated dimensional is also not significant. But the relationship between loneliness and interest in online sexual behavior is significant.

Keywords: cybersex, emerging adult, loneliness

Buletin Penelitian Psikologi dan Kesehatan Mental (BRPKM), 2021, Vol. 1(1), 723-733

*Alamat korespondensi: Fakultas Psikologi Universitas Airlangga, Kampus B Universitas Airlangga Jalan Airlangga 4-6 Surabaya 60286. Surel: afif.kurniawan@psikologi.ac.id 
sehingga penggunaan, distribusi, reproduksi dalam media apapun atas artikel ini tidak dibatasi, selama sumber aslinya disitir dengan baik.

\section{P E N D A H U L U A N}

Internet telah menjadi sebuah kebutuhan bagi kehidupan masyarakat, internet bahkan telah mempengaruhi berbagai bidang seperti sosial, budaya, pendidikan dan yang lainnya. namun disamping itu, internet juga memiliki berbagai macam dampak negatif seperti terbukanya akses pornografi. Selama masa pandemi diketahui tingkat pengaksesan pornografi semakin meningkat, Pornhub menjelaskan terjadi peningkatan akses pornografi yang mereka sediakan sebanyak 11,6\% pada bulan Maret 2020 (Pornhub, 2020). Bahkan peningkatan yang terjadi berawal sejak bulan Februari, 2020. Dari data yang didapat dijelaskan pula bahwa peningkatan pengaksesan pornografi terjadi sebanyak 4-24\% pada 27 negara. Dengan adanya program Pornhub mengenai premium akses tanpa bayar karena adanya tuntutan lockdown dan karantina dirumah, terjadi peningkatan intensitas menjadi sebanyak 57\% di Negara Italia, 38\% di Perancis dan 61\% di Spanyol. Pada tanggal 17 bulan Maret 2020, Pornhub juga mengamati adanya perubahan pola dari konsumsi pornografi di daerah Eropa, dimana waktu pengaksesan pornografi terbesar terjadi pada pukul 3 pagi $(31,5 \%)$ dan pukul 1 siang $(26,4 \%)$.

Sebuah penelitian yang dilakukan di Amerika Serikat menjelaskan bahwa ada sekitar 93\% dari laki-laki dan 62\% dari perempuan pernah mengakses konten pornografi secara online dalam masa remajanya, dan kelompok laki-laki dinyatakan mengakses konten pornografi lebih awal daripada perempuan (Wolak dkk., 2007). Dalam penelitian yang lain juga dijelaskan bahwa kurang lebih 60\% dari laki-laki dan 35\% perempuan pernah melihat konten pornografi sebelumnya (Price dkk., 2016). Penelitian dari Family Safe Media (2010) membuktikan bahwa setiap 1 dari 3 orang yang mengunjungi situs pornografi adalah wanita. Dan 60\% dari wanita yang menggunakan search engine mencari berbagai hal tentang seks, banyak juga anak yang masih berusia dibawah 18 tahun kerap mencari tahu pengetahuan tentang seks. Sekitar $42.7 \%$ pengguna internet mengakses konten pornografi, dan $25 \%$ dari pengguna search engine memanfaatkan untuk mencari konten pornografi yang spesifik (Ropelato, 2014).

Indonesia adalah salah satu negara pengakses pornografi terbesar, Menurut data tahunan Kementrian Komunikasi dan Informatika (kominfo) tahun 2016 menyebutkan bahwa ada setidaknya 768.235 kunjungan situs pornografi dan terjaring layanan internet positif. Indonesia menempati posisi ketiga negara pengakses pornografi di dunia (Kementerian Komunikasi dan Informatika, 2014). Menurut sumber yang lain menjelaskan bahwa paparan pornografi di Indonesia terjadi sekitar 63.066 melalui instagram, media online dan berbagai situs lainnya. Dari data tersebut juga disebutkan bahwa pengakses terbesar rata-rata adalah pelajar SMP dan SMA yang berusia remaja dengan persentase sebesar $97 \%$. Berdasarkan penjelasan tersebut dijelaskan bahwa banyak sekali pengguna internet yang tidak menggunakan internet dalam hal positif, melainkan memanfaatkan internet sebagai salah satu media untuk mengakses konten pornografi. Ditemukan juga bahwa pengakses pornografi terbesar didominasi oleh remaja.

Pornografi termasuk dalam salah satu bentuk cybersex. Menurut Madden (dalam Attwood, 2009) menjelaskan cybersex sebagai kombinasi antara seks dan teknologi. Cybersex meliputi banyak kegiatan yang dapat dilakukan oleh individu yang bertujuan untuk kegiatan seksual, meliputi pesan (chatting) dengan konteks seksual, melihat konten-konten seksual (pornografi) secara online, mendownload konten-konten seksual, bertukar konten-konten seksual atau melakukan foreplay dalam suatu chatroom 
tertentu. Carnes, dkk., (2007) memaparkan bahwa cybersex terdiri atas tiga kategori, yaitu mengakses pornografi secara online, real time dengan pasangan fantasi, dan menggunakan perangkat lunak multimedia.

Delmonico \& Miller (2003) mengembangkan alat ukur mengenai cybersex yang memuat tujuh dimensi dari perilaku cybersex, yaitu yang pertama adalah online sexual compulsivity, yang menjelaskan mengenai perilaku seksual online individu yang bersifat kompulsif. Dimensi kedua yaitu online sexual behavior-social, yang menjelaskan mengenai interaksi interpersonal yang dimiliki oleh seseorang dengan yang lainnya ketika melakukan cybersex. online sexual behavior-isolated menjelaskan mengenai perilaku seksual online yang dilakukan tanpa adanya hubungan sosial dengan orang lain. Online sexual spending menjelaskan mengenai kecenderungan individu dalam mengeluarkan biaya untuk konten seksual. Interest in online sexual behavior, menjelaskan ketertarikan individu terhadap perilaku seksual online. Non-home computer use, yaitu kecenderungan individu untuk menggunakan komputer di luar rumah mereka, dan dimensi yang terkahir yaitu accessing illegal sexual material, yang menjelaskan mengenai perilaku seksual online yang dianggap ilegal seperti mengakses konten dan materi pornografi secara ilegal.

Cooper, dkk., (1999) menyatakan alasan mendasar seseorang melakukan cybersex karena 3 alasan utama yang sering disebut dengan Triple A, yaitu accesibility, annonimity, dan affordability. Accesibility artinya cybersex sangat mudah diakses di internet, banyak sekali media atau aplikasi yang dapat dimanfaatkan seseorang untuk berbagi konten seksual. Annonimity yaitu perilaku cybersex dapat dilakukan secara anonim, dimana seseroang tidak perlu membagikan identitasnya. Sedangkan affordability maksudnya adalah cybersex dinilai cenderung lebih murah dibandingkan yang lainnya. Selain alasan utama diatas, terkadang Individu melakukan cybersex terkadang hanya menginginkan companionship (teman berbincang, friendly talking dan yang lainnya) yang dimana ini adalah tahap awal dari cybersex, dan pada akhirnya berlanjut kepada intensi seksual (Attwood, 2009).

Menurut Schwartz \& Southern (2000) juga mengatakan bahwa individu melakukan perilaku seksual secara online untuk melepaskan tekanan mereka, paling tidak mereka melakukan cybersex sebagai pelarian dari kebosanan, kesepian dan kekosongan yang mereka alami. Sebagai salah satu tugas perkembangan bagi emerging adult, yaitu intimacy, maka individu pada emerging adult berusaha membuat diri mereka memiliki seseorang yang dekat dengan mereka, sebagai hal untuk menghindari loneliness dan memenuhi tugas perkembangan mereka. Loneliness merupakan pengalaman subjektif dan tergantung pada intepretasi individu, dan setiap orang memiliki pengalaman loneliness yang berbeda-beda serta perasaan dirugikan dan tidak terpuaskan yang dihasilkan dari kesenjangan antara hubungan sosial yang diinginkan dan hubungan sosial yang dimiliki. Salah satu konsep dari loneliness yaitu need for intimacy, yaitu kebutuhan seseorang untuk menjalin hubungan dan kedekatan atau keakraban, kesepian dipandang sebagai suatu perasaan sepi dari tidak terpenuhinya kebutuhan dengan keakraban orang lain (Ghaisani, 2016). Cybersex sering dimanfaatkan untuk memperoleh teman dekat, pasangan sehingga mereka dapat merasa tidak gagal dalam proses perkembangan yang mereka alami.

Menurut Ceyhan \& Ceyhan (2008), menyatakan bahwa loneliness adalah salah satu variabel prediksi dari permasalahan internet. Selain itu penelitian lainnya juga menyatakan bahwa loneliness berkorelasi positif terhadap penggunaan alat komunikasi elektrik (Smith \& Shwalb, 2007). Sedangkan menurut Young (1998) online relationship terkadang dilihat memiliki intimasi yang lebih confidential dan tidak terlalu mengancam dan dianggap dapat mengurangi kesepian yang dialami oleh seseorang. Survei yang lain juga membuktikan bahwa group individu yang mengalami adiksi terhadap internet memiliki rasa 
kesepian yang tinggi dan skill sosial yang buruk. Loneliness juga dianggap memiliki pengaruh terhadap lamanya seseorang menghabiskan waktu untuk mengakses internet. Banyak penelitian yang telah menjelaskan bahwa adanya hubungan antara loneliness dengan perilaku cybersex, terutama dimasa pandemi seperti ini, tingkat loneliness mengalami peningkatan sehingga memungkinkan pula terjadinya peningkatan terhadap perilaku cybersex.

Tujuan dari penelitian ini adalah untuk mengetahui dan menguji hubungan antara tingkat loneliness dengan perilaku cybersex, disamping itu pada penelitian ini juga dilakukan untuk mengetahui hubungan antara tingkat loneliness dengan tiga dimensi dari perilaku cybersex, yaitu online sexual behavior-social, online sexual behavior-isolated, dan interest in online sexual behavior.

Sehingga dapat dijelaskan secara terperinci hipotesis dalam penelitian ini meliputi:

Hipotesis Umum:

$\mathrm{H}_{1}$ : Ada hubungan antara loneliness dengan perilaku cybersex pada emerging adult.

Hipotesis Khusus:

$\mathrm{H}_{1 \mathrm{a}}$ : Ada hubungan antara loneliness dengan dimensi online sexual behavior-social.

$\mathrm{H}_{1 \mathrm{~b}}$ : Ada hubungan antara loneliness dengan dimensi online sexual behavior-isolated.

$\mathrm{H}_{1 \mathrm{c}}$ : Ada hubungan antara loneliness dengan dimensi interest in online sexual behavior.

\section{Desain Penelitian}

\section{E T O D E}

Penelitian ini dilakukan dengan menggunakan pendekatan kuantitatif yang menghasilkan data dalam bentuk angka serta adanya uji hipotesis, dalam penelitian kuantitatif data dapat berupa analisa statistik, tabel, atau diagram dengan menghubungkan hubungan dari hasil terhadap hipotesa yang disusun (Neuman, 2007). Berdasarkan tujuan penelitian, tipe penelitian dalam penelitian ini menggunakan tipe penelitian penjelasan (explanatory research), dengan metode survei sebagai metode pengambilan data. Tipe penelitian eksplanatori dilakukan untuk mengetahui kejelasan dari sebuah masalah yang telah diketahui dan menjelaskan kausal atau sebab akibat antar variabel melalui uji hipotesis (Neuman, 2007).

\section{Partisipan}

Populasi dalam penelitian menggunakan beberapa karakteristik tertentu yaitu laki-laki dan perempuan belum menikah dan pernah melakukan perilaku cybersex (melihat dan/atau mendownload konten seksual dalam bentuk teks/cerita, gambar, audio, dan/atau mengirim, tukar/menukar chatting seksual dengan orang lain). Sedangkan, karakteristik demografis yang digunakan meliputi usia partisipan (1825 tahun), dan tingkat pendidikan. Peneliti menggunaan teknik sampling menggunakan purposive sampling, yaitu tipe pengambilan sampel dimana partisipan diperoleh karena memenuhi kriteria yang telah ditentukan oleh peneliti (Morissan, 2012). Penentuan jumlah sampel dibantu menggunakan perhitungan $G^{*}$ Power 3.1 dengan level signifikansi sebesar 0,05 serta level power sebesar 0,95. Hasil hitungan $G^{*}$ power diperoleh bahwa minimum dalam penelitian dibutuhkan sebanyak 153 partisipan.

\section{Teknik Pengumpulan Data}

Penelitian ini menggunakan teknik pengumpulan data survei, yaitu cara pengumpulan data yang dilakukan dengan cara mengetahui respon dari subjek yang dapat dilakukan dengan mengetahui respon dari subjek yang dapat dilakukan dengan mengisi sebuah kuesioner tertentu dalam penelitian. Survei yang dilakukan dalam penelitian ini dilakukan secara online dengan memanfaatkan fitur Google Form. 
Menurut Neuman (2017) menjelaskan beberapa kelebihan dari penggunaan metode survei yaitu hemat dalam segi tenaga, waktu dan biaya, dapat mencangkup desain geografis yang luas, memungkinkan desain yang fleksibel, responden leluasa menjawab kuesioner. Penelitian ini juga menyertakan informed consent, sehingga dalam pengisian survei, partisipan dapat dipastikan dalam keadaan sadar tanpa adanya paksaan.

\section{Pengukuran}

Alat ukur yang digunakan untuk mengukur variabel loneliness dalam penelitian ini menggunakan skala unidimensi UCLA Loneliness Scale Ver. 3 yang dikembangkan oleh Russell (1996). UCLA Loneliness scale terdiri atas 20 pernyataan yang bersifat self-report, dimana individu dapat mendeskripsikan apa yang dialami dan dirasakan olehnya terkait pernyataan yang diberikan. Individu dapat memiliki 4 opsi respon (1="tidak pernah", 2="jarang", 3="kadang-kadang" dan 4="selalu") dengan koefisien reliabilitas yang cukup baik $(\alpha=0,872)$

Alat ukur yang digunakan untuk mengukur perilaku cybersex menggunakan skala Internet Sex Screening Test (ISST) yang dikembangkan oleh Delmonico (1997). Alat ukur ISST ini merupakan self-report yang bersifat multidimensi, yang terdiri atas 7 dimensi, dan pada penelitian ini hanya digunakan 3 dimensi dari alat ukur ISST yaitu online sexual behavior-social, online sexual behavior-isolated dan interest in online sexual behavior. Individu dapat memberikan respon "ya" atau "tidak" dalam setiap pernyataan yang diberikan. Hasil uji reliabilitas skala ISST dengan 3 dimensi diperoleh hasil yang cukup baik $(\alpha=0,634)$

\section{Analisi Data}

Penelitian ini menggunakan tipe penelitian kuantitatif dengan metode survei, sehingga hasil penelitian yang didapatkan berupa angka, sehingga diperlukan analisis statistik yang berfungsi untuk mengolah data yang diperoleh. Peneliti menggunakan teknik analisis daya untuk menguji hubungan yang dimiliki antara loneliness dengan perilaku cybersex pada emerging adult, uji analisis yang dilakukan yaitu melalui uji korelasi untuk mengetahui hubungan antar variabel. Perhitungan dan analisis daya dilakukan dengan menggunakan program IBM SPSS versi 22.0 for Windows.

\section{HAS IL PENELITIAN}

\section{Analisis Deskriptif}

Penelitian ini memperoleh 189 partisipan $\left(\mathrm{N}_{\text {laki-laki }}=112 ; \mathrm{N}_{\text {perempuan }}=75 ; \mathrm{N}_{\text {lainnya }}: 2\right)$ yang memenuhi kriteria yaitu berusia 18-25 tahun dan pernah melakukan cybersex, dimana partisipan didominasi oleh individu yang berusia 21 tahun $\left(\mathrm{N}_{21}=72\right)$. Pada data status pendidikan, partisipan didominasi oleh mahasiswa $\left(\mathrm{N}_{\text {mahasiswa }}=159\right)$. Berdasarkan analisis deskriptif yang telah dilakukan, diperoleh nilai mean atau rata-rata pada variabel loneliness sebesar 40,95 dan mean pada variabel cybersex sebesar 4,44. Sedangkan nilai SD atau standar deviasi yang diperoleh pada variabel loneliness yaitu 9,328 dan SD pada variabel cybersex diperoleh sebesar 2,122. Selain itu dalam analisis deskriptif juga diperoleh nilai skewness, yaitu menunjukkan indikasi simetris suatu distribusi, nilai skewness pada variabel loneliness diperoleh sebesar 0,574 dan skewness pada variabel cybersex diperoleh 0,352 yang artinya keduanilai ini memuat angka 0 sehingga dapat dikatakan bahwa data bersifat normal. Sedangkan nilai kurtosis menunjukkan tingkat keruncingan sebuah data, pada variabel loneliness diperoleh kurtosis sebesar 
0,510 dan pada cybersex memperoleh nilai kurtosis sebesar 0,400 yang artinya kedua nilai ini bersifat positif sehingga data cenderung mengumpul di tengah (Pallant, 2011).

\section{Uji Asumsi}

Uji asumsi yang dibutuhkan dalam penelitian ini yang pertama adalah uji normalitas, uji normalitas dilakukan untuk mengetahui distribusi data dalam variabel yang digunakan dalam penelitian (Pallant, 2011). Berdasarkan uji normalitas yang dilakukan diketahui bahwa nilai signifikansi yang diperoleh pada variabel loneliness sebesar $(\mathrm{p}=0,2)$ yang artinya data pada variabel loneliness bersifat normal karena memiliki nilai $(p>0,05)$. Sedangkan pada variabel cybersex diperoleh nilai $(p=0,00)$ yang menjelaskan bahwa data yang diperoleh bersifat tidak normal $(\mathrm{p}<0,05)$.

Uji asumsi lain yang dibutuhkan sebelum dilakukan uji hipotesis yaitu uji linearitas. Uji linearitas dilakukan untuk mengetahui hubungan antar dua variabel apakah bersifat linear atau tidak. Hubungan yang linear artinya hubungan terjadi ketika perubahan variabel tertentu akan mengakibatkan perubahan yang sama pada variabel lainnya. berdasarkan uji linearitas yang dilakukan diperoleh signifikasi linearitas sebesar $(p=0,519)$ artinya bahwa data yang dimiliki bersifat linear karena nilai yang diperoleh $(p>0,05)$ (Widhiarso, 2010).

\section{Uji Korelasi}

Dikarenakan data bersifat tidak normal, peneliti menggunakan teknik bootstraping untuk mereduksi bias, dimana bootstrapping merupakan sebuah teknik berbasis komputer yang digunakan untuk mereplikasi sampel dari data yang kita peroleh secara acak untuk diperoleh data simulasi yang baru (Fook Chong \& Choo, 2011). Sehingga dengan teknik bootstraping ini tidak diperlukan uji asumsi lainnya, berbeda dengan metode tradisional yang mengharuskan melakukan beberapa uji asumsi. Teknik bootstrapping ini didukung dengan central limit theorem yang menjelaskan semakin besar sampel, maka distribusinya semakin normal. Wilcox (2010) menjelaskan seberapa besar sampel yang dibutuhkan untuk central limit theorem, secara umum sampel yang dibutuhkan adalah 30, namun hal ini juga bergantung pada distribusi populasi, pada distribusi dengan outliers yang sedikit, 20 sampel sudah dianggap banyak, tetapi pada distribusi dengan sampel yang memiliki cukup banyak outliers, 100 hingga 160 sampel sudah dianggap cukup banyak. Sehingga dalam penelitian ini uji korelasi dilakukan dengan metode bootstrap.

Berdasarkan uji korelasi bootstrap yang dilakukan antara loneliness dengan cybersex diketahui bahwa hubungan yang dimiliki bersifat tidak signifikan (r(1000)=0,111; 95\% CI $[-0.037 ; 0,242] ; \mathrm{p}=0,128)$ hal ini dikarenakan nilai lower dan upper dari hasil uji korelasi pearson menggunakan metode bootstrap mengandung nilai 0.

Uji korelasi yang dilakukan antara variabel loneliness dengan dimensi online sexual behavior-social pada variabel cybersex menjelaskan bahwa hubungan yang dimiliki bersifat tidak signifikan $(\mathrm{r}(1000)=-0,016$; $95 \%$ CI $[-0,140 ; 0,120] ; p=0,823)$, hal ini disebabkan karena nilai lower dan upper mengandung nilai 0.

Peneliti juga melakukan uji korelasi antara loneliness dengan dimensi kedua pada variabel cybersex yaitu online sexual behavior-isolated, dimana hubungan yang dimiliki bersifat tidak signifikan ( $\mathrm{r}(1000)=0,112$ ; 95\% CI $[-0,10 ; 0,236]$; $\mathrm{p}=0,123)$ yang mana nilai lower dan upper dari interval konfidensi memuat nilai 0. 
Terakhir, peneliti melakukan uji korelasi antara loneliness dengan dimensi ketiga pada variabel cybersex yaitu interest in online sexual behavior, dimana hubungan yang dimiliki bersifat signifikan $\operatorname{Cr}(1000)=0,215 ; 95 \%$ CI $[0,049 ; 0,372] ; \mathrm{p}=0,003)$ dimana nilai interval konfidensi lower maupun upper sama-sama bernilai positif.

\section{I S K U S I}

Berdasarkan penelitian dan anlisis yang telah dilakukan diketahui bahwa adanya tidak ada pengaruh antara loneliness dengan perilaku cybersex pada emerging adult. Hal ini disebabkan karena beberapa faktor yaitu, loneliness bukanlah satu-satunya faktor yang dapat mempengaruhi perilaku cybersex. banyak faktor yang mempengaruhi perilaku cybersex seperti adanya faktor ACE (Accessibility, Convenience dan Escape) dimana individu melakukan cybersex karena perilaku cybersex dianggap murah, mudah diakses, dan tanpa ikatan. Konsep ini hampir sama dengan konsep yang dijelaskan oleh Cooper dkk. (1999) yaitu mengenai Triple A (Accessibility, Affordability dan Annonimity), dimana individu yang melakukan cybersex dikarenakan cybersex dianggap murah, mudah diakses dan bersifat anonim.

Faktor lain yang menyebabkan hubungan yang dimiliki antara loneliness dengan perilaku cybersex adalah, respon dan reaksi individu terhadap perilaku cybersex berbeda-beda, yaitu yang pertama individu yang merasa kesepian terkadang melakukan kegiatan aktif dan berusaha untuk memanfaatkan situasi yang mereka alami untuk hal-hal yang positif dan produktif, disamping itu individu yang mengalami loneliness juga terkadang membuat kontak sosial seperti menghubungi rekan-rekan kerja atau orang-orang yang dekat dengan berbagai cara seperti menelfon, mengunjungi dan yang lainnya. selain itu, individu yang merasa loneliness terkadang juga melakukan kegiatan pasif seperti menangis, tidur, duduk dan berfikir. Respon lain yang dapat dimunculkan oleh individu yang mengalami perasaan loneliness yaitu dengan kegiatan selingan yang kurang membangun seperti menghabiskan uang, mencari konten pornografi, berbelanja dan yang lainnya (Brehm, 1992).

Dari berbagai hasil penelitian diatas, dijelaskan bahwa respon loneliness setiap individu berbeda dan tidak hanya melakukan perilaku yang negatif saja (seperti melakukan perilaku cyebrsex), disamping itu alasan individu melakukan cybersex juga berbeda-beda. Sehingga dapat disimpulkan bahwa hipotesis utama yaitu adanya hubungan antara loneliness dengan perilaku cybersex pada emerging adult tidak terkonfirmasi.

Peneliti juga melakukan uji hubungan antara loneliness dengan dimensi online sexual behavior social, salah satu perilaku yang mencerminkan dimensi ini yaitu perilaku sexting (chat sex), dimana hubungan yang dimiliki bersifat tidak signifikan karena tingkat loneliness bukanlah satu-satunya faktor penyebab perilaku sexting. Penelitian yang dilakukan oleh Kindred \& Roper (2004) tentang penggunaan pesan instan (instant messaging) pada mahasiswa, ditemukan bahwa banyak dari mahasiswa memanfaatkan pesan instan untuk berkomunikasi, mempertahankan hubungan dan memperkuat relasi dengan temanteman mereka. Parker, dkk. (2013) juga menjelaskan bahwa tujuan utama individu melakukan sexting adalah selain sexting merupakan salah satu cara memuaskan hasrat mereka, sexting juga dilakukan untuk mencapai intimasi dan sebagai afirmasi.

Selain itu, Parker, dkk (2013) juga menjelaskan bahwa perilaku sexting dapat meningkatkan kualitas hubungan individu. Sehingga dapat diketahui bahwa banyak faktor lain yang sebenarnya dapat mempengaruhi perilaku sexting, selain loneliness. Dan bahkan individu justru memanfaatkan perilaku sexting untuk menjalin banyak interaksi dan hubungan dengan orang lain, serta meningkatkan 
kepuasan individu dalam berhubungan, baik dengan orang lain maupun dengan pasangan. Berdasarkan penjelesalan tersebut maka hipotesis khusus pertama mengenai adanya hubungan antara loneliness dengan dimensi online sexual behavior-social tidak terkonfirmasi.

Dimensi selanjutnya yaitu online sexual behavior-isolated, contoh perilaku yang mencerminkan dimensi ini yaitu seperti perilaku menonton pornografi dan yang lainnya. Hubungan yang dimiliki bersifat tidak signifikan karena banyak sekali faktor yang memengaruhi pengaksesan pornografi, sehingga loneliness bukanlah satu-satunya alasan mengapa individu mengakses pornografi, bahkan dalam berbagai penelitian menjelaskan bahwa faktor utama penyebab individu mengakses pornografi adalah adanya hasrat seksual (sexual arousal) (Boies, 2002). Faktor lain yang menyebabkan individu melakukan pengaksesan terhadap pornografi, yaitu mencari hiburan seksual, gratifikasi seksual, masturbasi, untuk membuat seks lebih menyenangkan, untuk memahami lebih dalam tentang seks (Burns, 2001). Sehingga hipotesis khusus kedua yaitu adanya hubungan antara loneliness dengan dimensi online sexual behavior-isolated tidak terkonfirmasi.

Terakhir, peneliti melakukan uji korelasi dengan dimensi interest in online sexual behavior yang menjelaskan mengenai ketertarikan individu terhadap perilaku seksual online. Hubungan yang dimiliki bersifat signifikan dan berarah positif. Hal ini dapat terjadi karena semakin tinggi tingkat loneliness individu, individu akan berusaha menekan dan mengurangi perasaan loneliness yang dialaminya (Amichai-Hamburger, 2017). Sebagai upaya menangani perasaan loneliness yang dialaminya, individu kerap memanfaatkan internet, salah satu upaya yang sering dilakukan untuk mengatasi perasaan loneliness ini dengan melakukan kegiatan seksual online (pornografi dan cybersex) (Delmonico \& Griffin, 2012). Selain itu, untuk mengurangi perasaan loneliness yang dialami olehnya, individu juga kerap memanfaatkan internet untuk kegiatan seksual online lainnya aktivitas chatting sex pada sebuah chatroom tertentu pornografi, atau berhubungan dan bertemu dengan orang lain secara langsung (Barak dkk., 1999). Sehingga hipotesis khusus ketiga terkonfirmasi.

\section{S I M P U L A N}

Berdasarkan hasil penelitian yang diperoleh, dapat disimpulkan bahwa hubungan antara tingkat loneliness dengan perilaku cybersex pada emerging adult tidak signifikan. Peneliti juga melakukan analisis antara loneliness dengan ketiga dimensi dari variabel cybersex, yaitu online sexual behaviorsocial, online sexual behavior-isolated dan interest in online sexual behavior. Hasil penelitian menunjukkan bahwa ada hubungan yang signifikan antara loneliness dengan dimensi interest in online sexual behavior, namun hubungan yang terjadi antara loneliness dengan variabel online sexual behaviorsocial, online sexual behavior-isolated bersifat tidak signifikan.

Saran bagi penelitian selanjutnya dapat melakukan penelitian yang serupa menggunakan variabel lain yang tidak diteliti dalam penelitian ini seperti faktor lain yang dapat mempengaruhi respon loneliness individu, maupun faktor lain yang mempengaruhi perilaku cybersex, sedangkan saran untuk pemerintah dan pembuat kebijakan internet agar dapat lebih memperhatikan konten-konten yang tersebar di internet agar aman untuk dikonsumsi masyarakat. Serta saran bagi psikolog dan praktisi psikologi agar dapat melakukan psikoedukasi mengenai berbahayanya perilaku cybersex tertama di kalangan remaja, serta dapat membantu individu yang mengalami permasalahan dengan perilaku cybersex. 


\section{U C A P A N T ER I MAKASIH}

Penulis mengucapkan terimakasih kepada partisipan yang telah berkenan membantu penelitian sehingga dapat terselesaikan dengan baik. Semoga penelitian ini dapat berguna untuk pengembangan ilmu dan penelitian yang selanjutnya, serta bagi pemerintah dan pembuat kebijakan internet, serta masyarakat luas, terutama emerging adult.

\section{DEKLARAS I POTENSI TER JADINYA KONFLIK KEPENTINGAN}

Laily Aura Nisya Habibi dan Afif Kurniawan tidak bekerja, menjadi konsultan, memiliki saham, atau menerima dana dari perusahaan atau organisasi manapun yang mungkin akan mengambil untuk dari diterbitkannya naskah ini.

\section{P US T A KA A C UA N}

Amichai-Hamburger, Y. (2017). Internet Psychology. In Internet Psychology. https://doi.org/10.4324/9781315622163

Attwood, F. (2009). "Deepthroatfucker" and "discerning adonis": Men and cybersex. In International Journal of Cultural Studies (Vol. 12, Issue 3). https://doi.org/10.1177/1367877908101573

Barak, A., Fisher, W. A., Belfry, S., \& Lashambe, D. R. (1999). Sex, Guys, and Cyberspace: Effects of Internet Pornography and Individual Differences on Men's Attitudes Toward Women. Journal of Psychology and Human Sexuality, 11(1). https://doi.org/10.1300/J056v11n01_04

Boies, S. C. (2002). University students' uses of and reactions to online sexual information and entertainment: Links to online and offline sexual behaviour. Canadian Journal of Human Sexuality, 11(2).

Brehm, S. S. (1992). Intimate relationships, 2nd ed. In Intimate relationships, 2nd ed.

Burns, R. J. (2001). Male Internet pornography consumers and their attitudes toward men and women. Dissertation Abstracts International Section A: Humanities and Social Sciences, 62(5-A).

Carnes, P., Delmonico, D. L., \& Griffin, E. (2007). In the shadows of the net: Breaking free of compulsive online sexual behavior (2nd ed.). In In the shadows of the net: Breaking free of compulsive online sexual behavior (2nd ed.).

Ceyhan, A. A., \& Ceyhan, E. (2008). Loneliness, depression, and computer self-efficacy as predictors of problematic internet use. Cyberpsychology and Behavior, 11(6). https://doi.org/10.1089/cpb.2007.0255

Cooper, A., Putnam, D. E., Planchon, L. A., \& Boies, S. C. (1999). Online sexual compulsivity: Getting tangled in the net. Sexual Addiction and Compulsivity, 6(2). https://doi.org/10.1080/10720169908400182

Coronavirus Insights. (2020, March 23). Pornhub. https://www.pornhub.com/insights/corona-virus

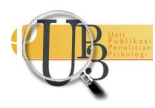


Delmonico, D. L. (1997). Cybersex: High tech sex addiction. Sexual Addiction and Compulsivity, 4(2). https://doi.org/10.1080/10720169708400139

Delmonico, D. L., \& Griffin, E. J. (2012). Cybersex Addiction and Compulsivity. In Internet Addiction. https://doi.org/10.1002/9781118013991.ch7

Delmonico, D. L., \& Miller, J. A. (2003). The Internet Sex Screening Test: A comparison of sexual compulsives versus non-sexual compulsives. Sexual and Relationship Therapy, 18(3). https://doi.org/10.1080/1468199031000153900

Fook Chong, S., \& Choo, R. (2011). Introduction to bootstrap. In Proceedings of Singapore Healthcare (Vol. 20, Issue 3). https://doi.org/10.1177/201010581102000314

Ghaisani, R. N. S. G. (2016). Hubungan Self Esteem dan Loneliness pada Remaja Akhir Pelaku Cybersex di Bandung. Psikologi, 1965.

Kementerian Komunikasi dan Informatika. https://kominfo.go.id/content/detail/4286/pengguna-internet-indonesia-nomor-enamdunia/0/sorotan_media

Kindred, J., \& Roper, S. L. (2004). Making Connections Via Instant Messenger (IM): Student Use of IM to Maintain Personal Relationships. Qualitative Research Reports in Communication, 5.

Morissan. (2012). Metode Penelitian Survey. Prenadamedia Group.

Neuman, W. L. (2007). Basics of Social Research Methods: Qualitative and Quantitative Approaches (2nd ed.). Allyn and Bacon.

Neuman, W. L. (2017). Metodologi Penelitian Sosial: Pendekatan Kualitatif dan Kuantitatif (ed. 7). Indeks.

Pallant, J. (2011). A step by step guide to data analysis using SPSS. Alen \& Unwin.

Parker, T. S., Blackburn, K. M., Perry, M. S., \& Hawks, J. M. (2013). Sexting as an Intervention: Relationship Satisfaction and Motivation Considerations. American Journal of Family Therapy, 41(1). https://doi.org/10.1080/01926187.2011.635134

Pornography Statistic. (2010, January 25). Family Safe $\quad$ Media. http://www.familysafemedia.com/pornography statistics.html

Price, J., Patterson, R., Regnerus, M., \& Walley, J. (2016). How much more XXX is generation X consuming? Evidence of changing attitudes and behaviors related to pornography since 1973. Journal of Sex Research, 53(1). https://doi.org/10.1080/00224499.2014.1003773

Ropelato, J. (2014). Internet Pornography Statistics. http://web.archive.org/web/20130121221924/http://internet-filterreview.toptenreviews.com/internet-pornography-statistics.html 
Russell, D. W. (1996). UCLA Loneliness Scale (Version 3): Reliability, validity, and factor structure. Journal of Personality Assessment, 66(1). https://doi.org/10.1207/s15327752jpa6601_2

Schwartz, M. F., \& Southern, S. (2000). Compulsive cybersex: The new tea room. Sexual Addiction and Compulsivity, 7(1-2). https://doi.org/10.1080/10720160008400211

Smith, T. B., \& Shwalb, D. A. (2007). Preliminary examination of international students' adjustment and loneliness related to electronic communications. Psychological Reports, 100(1). https://doi.org/10.2466/PR0.100.1.167-170

Widhiarso, W. (2010). Uji Linearitas Hubungan. Fakultas Psikologi UGM. http://widhiarso.staff.ugm.ac.id/files/widhiarso_2010_-_uji_linieritas_hubungan.pdf

Wilcox, R. R. (2010). Fundamentals of modern statistical methods: Substantially improving power and accuracy. In Fundamentals of Modern Statistical Methods: Substantially Improving Power and Accuracy. https://doi.org/10.1007/978-1-4419-5525-8

Wolak, J., Mitchell, K., \& Finkelhor, D. (2007). Unwanted and wanted exposure to online pornography in a national sample of youth internet users. Pediatrics, 119(2). https://doi.org/10.1542/peds.20061891

Young, K. S. (1998). Internet addiction: The emergence of a new clinical disorder. Cyberpsychology and Behavior, 1(3). https://doi.org/10.1089/cpb.1998.1.237 